\title{
FABRICATION AND CHARACTERIZATION OF LTCC BASED ON TALK GLASSES
}

\author{
Farhad M. O. Kushnaw \\ 130031@uotechnology.edu.iq \\ University of Technology, Department of Materials engineering
}

\begin{abstract}
In this work, fabrication of low temperature co-fired (LTCC) with different Talc content is performed. Density and mechanical characterization of the prepared samples has been examined. Three series of low temperature co-fired ceramics have been prepared. The glass part of these composites contains talc to enhance the mechanical properties. The densities, hardness and splitting strength are measured for these series to monitor the effect of composition on their properties. It is shown that the third series (Base3; Flint 25\%, talc 35\%, Pota ash 8\%, Soda ash 12\%, and Boric Acid 20\%) of the higher talc content shoes the better densities and mechanical properties. The results are explained in terms of better balance of the ceramic-class content that enhances the measured properties.
\end{abstract}

Keywords: LTCC, Sintering, Fabrication, Mechanical Properties, Glass ceramics.

\section{تصنيع وتوصيف سيراميك الـ (LTCC) ذو اساس زجاج الطلق.

$$
\text { فر هاد محمد عثمان }
$$

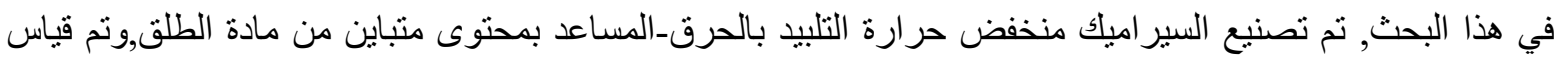

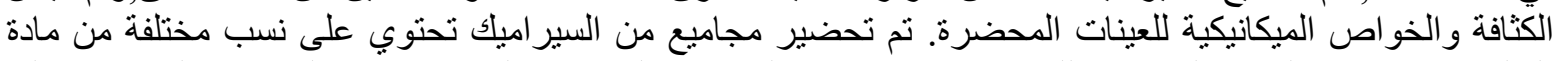

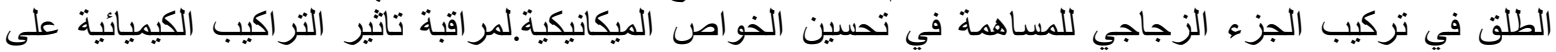

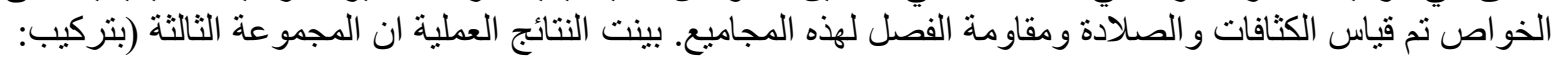
(Base3; Flint 25\%, talc 35\%, Pota ash 8\%, Soda ash 12\%, and Boric Acid 20\% العالي من مادة الطلق اظهرت كثافة وخو اص ميكانيكية جيدة. تم تفسيلر النتائج على اساس حدوث توازن في المحتوى

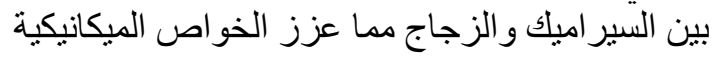




\section{INTRODUCTION}

Originally, low temperature co-fired ceramic (LTCC) technology stands for a glass ceramic composite with the intention of sintering temperature lower than $1000^{\circ} \mathrm{C}$. This type of composite have three main advantages; the first is that the low sintering temperature allows to fabricate metallic print circuits at temperature ranges below the risk of metal oxidization; the second is the high dielectric constant of these composites that prevents the 'cross-talk' between closely spaced 'wires' due to dielectric coupling; and the thirds is the relatively simple processing that relies on powder technology and allows production of multilayer substrates Moulson, (2003). LTCC technology is applied in electronic circuits as a costeffective and competitive substrate technology with nearly arbitrary number of layers. The multilayer ceramic stack will be fired (sintered) in the final manufacturing step Kulke, (2009). The interest in integrated passives derives from LTCC compositions with a sintering temperature no more than $900^{\circ} \mathrm{C}$ are in great demand in the field of highly integrated electronic components and modules. Most of the ceramics having a high dielectric constant and quality factor require high sintering temperature, while glass-only usually shows a low dielectric constant along with poor mechanical properties. In order to solve this problem, ceramic fillers are usually mixed with glass frits with low melting temperature to make the dielectric system co-firable with metal electrode Kim, (2008). LTCC also can be fabricated with integrated passives and has extendibility in the wiring and interconnection ground rules compared to those used today. LTCC will continue to be used in a variety of applications where it is best at meeting the cost and performance objectives sought by the customer Wessel, (2004). LTCC was primarily used in military and medical applications. The advent and explosion of wireless technology in the mid-1990s brought LTCC into the forefront for many commercial wireless products such as cellular phones and wireless local area network (WLAN). With very high pack aging density Fred, (2007); i.e., a significant packaging size reduction may be achieved by embedding passive materials within electronic LTCC modules Barth, (2009). Finally, LTCC technology did not dedicated only for dielectric applications. This technology finds widespread application where the need is for lower temperature maturing for ceramics with good physical and mechanical properties Saad, (2009). In this work, several compositions of glasses were produced. The starting materials for glass compositions includes Talc $\left(3 \mathrm{MgO} . \mathrm{SiO}_{2} . \mathrm{H}_{2} \mathrm{O}\right)$ that is known to help produce less porous bodies at lower firing temperatures and better mechanical properties. These glasses are used with burned kaolin to produce LTCC ceramics. The results for density, hardness and splitting (Brazilian) mechanical tests will be the guide for selecting the best samples ASTM, (2006).

\section{EXPERIMENTAL PART}

Three types of glasses are prepared in this work. Each type differs in their talc content. The difference in talc content is compensated by the flint (a silica quartz ore that contains about 98\% $\mathrm{SiO}_{2}$ and the remainder is kaolin, $\mathrm{CaO}, \mathrm{Na}_{2} \mathrm{O}$ and $\left.\mathrm{K}_{2} \mathrm{O}\right)$. Pota ash $\left(\mathrm{K}_{2} \mathrm{CO}_{3}\right)$, Soda ash $\left(\mathrm{Na}_{2} \mathrm{CO}_{3}\right)$ and Boric Acid $\left(\mathrm{B}_{2} \mathrm{O}_{3} \cdot 3 \mathrm{H}_{2} \mathrm{O}\right)$ is also included. Commercial grade (about $98 \%$ purity) powder starting materials are utilized to boost the significance of this work. Table (1) shows the weigh percentages of the starting materials for the three types of the glasses Base1, Base 2 and Base3. The powders are sieved to below $75 \mu \mathrm{m}$ via wire-mesh sieve, weighted according to table 1 and mixed with blade mixer. The powder batches are then melted in highalumina stone-ware porcelain crucibles at $1100^{\circ} \mathrm{C}$ for $30 \mathrm{~min}$. The glass melts are quenched in tap water, dried, crushed and milled with rotating cylinder miller and sieved to pass $50 \mu \mathrm{m}$. The produced glass powders are marked as Base 1 , Base 2 and Base 3 as mentioned above. The second phase of the preparation procedure begins with firing of Duekhla kaolin powder to $950^{\circ} \mathrm{C}$ for an hour in an alumina crucible. The resultant fired kaolin passes the $50 \mu \mathrm{m}$ sieve. The fired kaolin is used to prepare the mixes for LTCC composites as shown in Table (2). 
Obviously, the produced glass and the fired kaolin are both lack for plasticity and compressibility needed for powder die forming process. To overcome this obstacle a wet binder is prepared. The binder is composed of 50\% water and 50\% water glass (Sodium Silicate, density $\left.=1.5 \mathrm{~g} / \mathrm{cm}^{3}\right) .1 .2 \mathrm{ml}$ of binder is added to each $6 \mathrm{~g}$ of the powder mix shown in table 2 . Thoroughly mixed in a mortar and pressed by punch and die system. The diameter of the punch was $3 \mathrm{~cm}$ and the applied force was $100 \mathrm{~N}$. The resultant green pellets are then dried in $100^{\circ} \mathrm{C}$ for one hour followed by $400^{\circ} \mathrm{C}$ for another hour. Figure (1) shows the dried pellets before sintering. Each pellet is labeled with two numbers. The first (left) number refers to Base1, Base 2 and Base 3 ; and the second numbers refers to composition mentioned in Table 2. Then, sintering of the LTCC pellets were carried out in high temperature furnace at $850^{\circ} \mathrm{C}$ for one hour. In addition, the sintered pellets is subjected to geometrical density measurements utilizing 2-digit millimeter electronic Vernier and 4-digit balance, HR-30N hardness is measured and finally the splitting (Brazilian) mechanical test is measured according to ASTM D3967 standard test [ASTM, 2006]. The Brazilian test is performed utilizing Leybol-dheraves (Germany) apparatus at $7.5 \mathrm{kN}$.

\section{RESULTS AND DISSECTION}

It is found the sintering temperature of $850^{\circ}$ for one hour is optimum for the LTCC prepared in this work. Increasing the sintering temperature cause the melting of the prepared samples. Figure (2) shows the densities of the sintered sample versus glass content, where the glass was Base1, Base 2 and Base3. Each type of used glass led to different behavior. The densities of the sintered samples at the lower glass content (40\%) used in this study are close in value. In addition, the densities are increased with the glass content and the maximum densities are recorded at $80 \%$ glass content when using either type of glass. The samples that prepared with Base 3 glass show higher densities as the glass content increased. These results suggest that better balance of the ceramic-class content that help better stabilization of the microstructure with Base3 glass. Figure (3) shows the hardness test for the same series of the sintered sample. Obviously the series contains Base 3 glass show better behavior. That is, the hardness is better with higher glass content for the series with Base3 glass. The other series shows slower increasing of the hardness as the glass content increased. These results show that both the density and hardness increases with higher class content especially for Base 3 series. For further inspection of the properties of the prepared LTCC samples the splitting strength is examined. The results of the splitting strength of the prepared samples are shown in figure (4). The observed behavior shows clear enhancement of the splitting strength with the glass content and the Base 3 series show the best results. This confirms the above mentioned conclusion that better balance of the ceramic-class content of Base 3 series can be the reason for enhancement of density, hardness and splitting strength.

\section{CONCLUSIONS}

From the obtained results, the following conclusions can be drawn:

1. The density, hardness and splitting strength is increased with the glass content of the prepared LTCC in this work with glass content of $80 \%$ being the optimum.

2. Base 3 (Base3; Flint 25\%, talc 35\%, Pota ash 8\%, Soda ash 12\%, and Boric Acid 20\%) series shows the better properties for density, hardness and splitting strength due to higher talc content in the starting materials. 
Table (1): Weight percentages for glass starting materials

\begin{tabular}{|l|c|c|c|}
\hline Material & Base1 & Base2 & Base3 \\
\hline \% Flint & 35 & 30 & 25 \\
\hline Talc & 25 & 30 & 35 \\
\hline \% Pota ash & 8 & 8 & 8 \\
\hline \% Soda ash & 12 & 12 & 12 \\
\hline \% Boric Acid & 20 & 20 & 20 \\
\hline
\end{tabular}

Table (2): weight percentages for LTCC materials, \%Glass stands for Base 1, Base 2 and Base 3 percentages.

\begin{tabular}{|c|c|c|}
\hline Sample & \% Glass & \% fired kaolin \\
\hline 1 & 40 & 60 \\
\hline 2 & 50 & 50 \\
\hline 3 & 60 & 40 \\
\hline 4 & 70 & 30 \\
\hline 5 & 80 & 20 \\
\hline
\end{tabular}

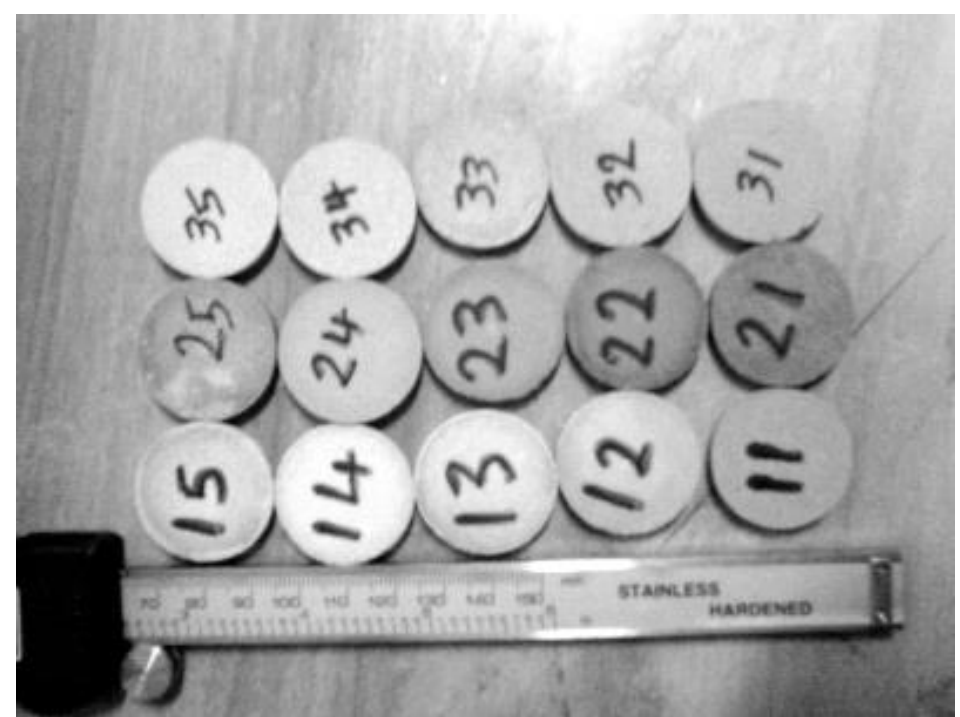

Fig. (1): The compacted and dried pellets are shown, where the bottom raw includes Base1 glass, the middle raw includes Base2 and the top raw includes Base3. 


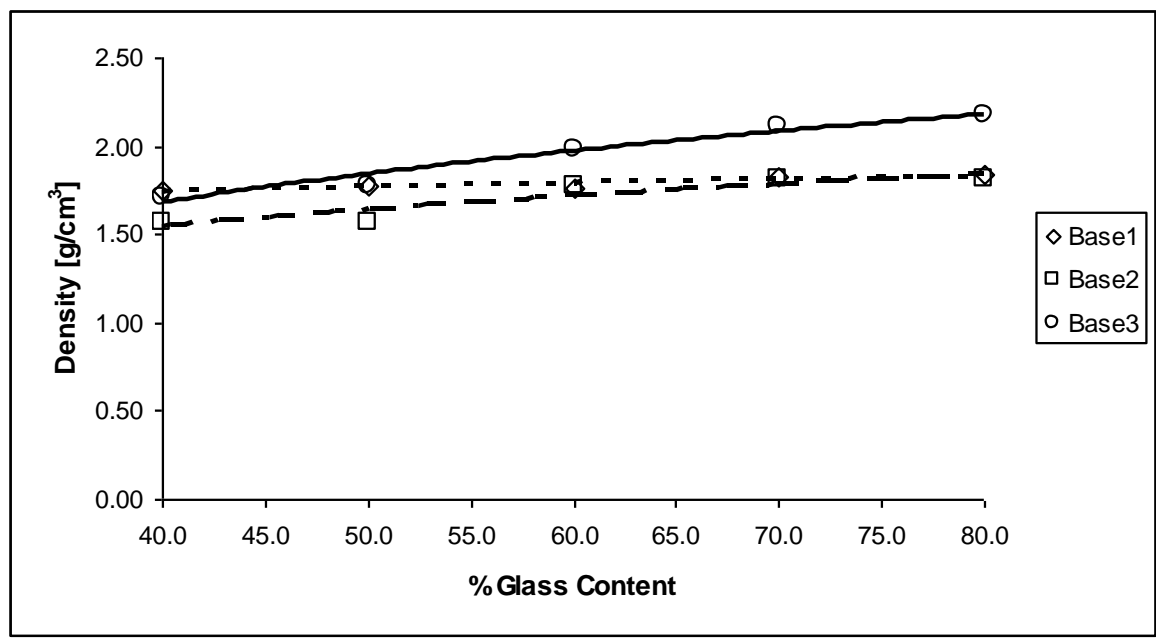

Fig. (2): The sintered densities of the prepared LTCC.

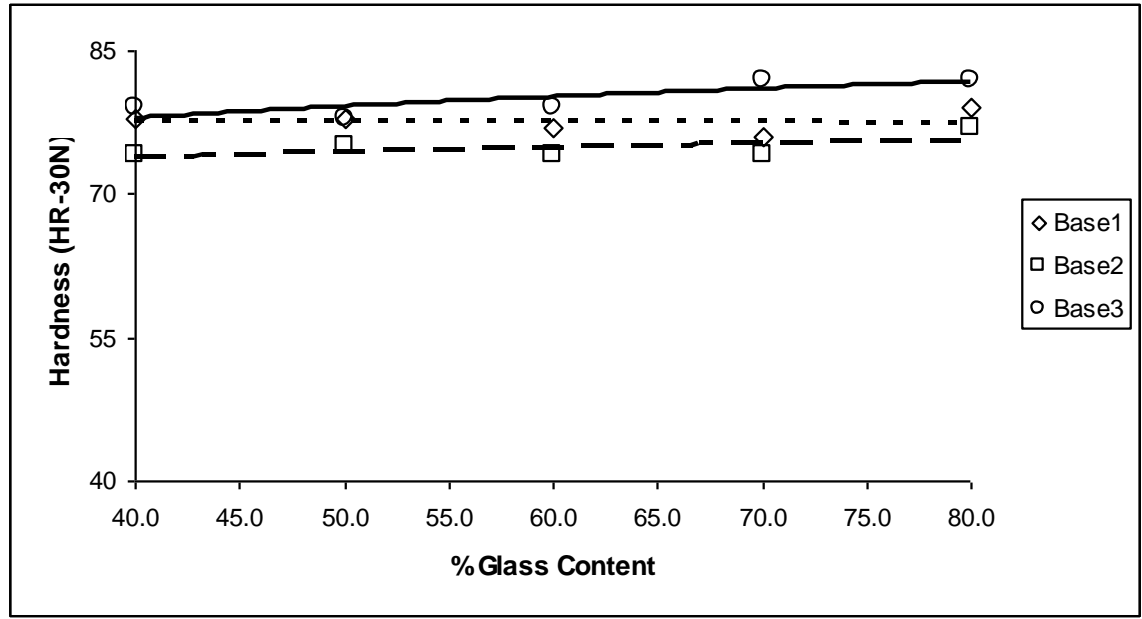

Fig. (3): Measured Hardness of the prepared Ceramics.

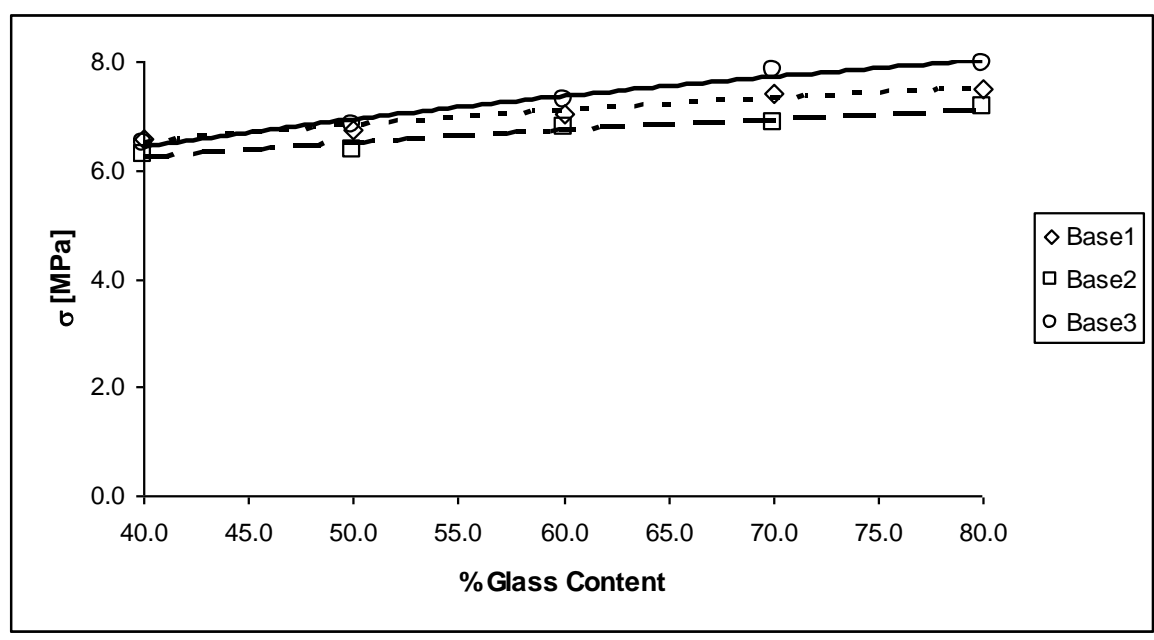

Fig. (4): Splitting Strength of the prepared Ceramics. 


\section{REFERENCES}

Barth S., Arnold M., Grützmann D., Pawlowski B., and Rothe P., "Low-Sintering High-k Materials for an LTCC Application", Int. J. Appl. Ceram. Technol., Vol.6, No.1, pp.35-40, 2009.

Fred D. Barlow, III and Aicha Elshabini., "Ceramic interconnect technology handbook" Taylor \& Francis Group LLC, p.35, 2007.

Kim J. H., Kwon S. W., Kim H. T. and Yoon D. H., "Modification of an AluminoBorosilicate Glass System Using Ceramic Additives For LTCC Application", CeramicsSilikáty, Vol. 52, No.3, pp. 139-147, 2008.

Kulke R. et al.: "LTCC - Multilayer Ceramic for Sensor and Wireless Applications, IMST $\mathrm{GmbH}, 2009$.

Moulson A. J. and Herbert J. M. "Electroceramics; Materials; Properties; Applications" Second Edition, John Wiley \& Sons Ltd, p.288, 2003.

Saad B. H. Farid, Gazi K. Saeed, Fadhil A. Chyad, "Effect of the Glassy Phase on the Properties of Porcelain", Proceeding of the second scientific conference of the university of Wassit, pp785-795, 2009.

The American Society for Testing and Materials, "ASTM Designation: D 3967 - 95aR2001 Standard Test Method for Splitting Tensile Strength of Intact Rock Core Specimens", Vol.4.08, 2006.

Wessel J. K., "Handbook of advanced materials: enabling new designs", John Wiley \& Sons, Inc., p.145, 2004. 